\title{
Fatigue Life Assessment of Tower Crane Based on Neural Network to Obtain Stress Spectrum
}

\section{YANG ZUO ( $\nabla$ zuoyang@126.com )}

Taiyuan University of Science and Technology

Feiyu Zhao

Shanxi University

Kaiyue Yang

Taiyuan University of Science and Technology

\section{Rongping Yang}

Taiyuan University of Science and Technology

\section{Research Article}

Keywords: crane, equivalent stress, actual parameters, cumbersome process, later maintenance, typical operating

Posted Date: November 30th, 2021

DOI: https://doi.org/10.21203/rs.3.rs-1074638/v1

License: (1) (1) This work is licensed under a Creative Commons Attribution 4.0 International License. Read Full License 


\title{
Fatigue Life Assessment of Tower Crane Based
}

\section{on Neural Network to Obtain Stress Spectrum}

\author{
Yang Zuo ${ }^{1,2}$,Feiyu Zhao ${ }^{3}$,Kaiyue Yang ${ }^{1}$,Rongping Yang ${ }^{1}$ \\ ${ }^{1}$ School of Mechanical Engineering, Taiyuan University of Science and Technology, Taiyuan China 030024, ${ }^{2} \mathrm{CHINA}$ RAILWAY \\ SIXTH GROUP CO.,LTD,Beijing China 100036, ${ }^{3}$ Shanxi University,School of Computer and Information Technology, Taiyuan \\ China 030024 \\ (Received 000 0, 2020; Revised 000 0, 2020; Accepted 000 0, 2020) \\ Keywords:Fatigue load spectrum; Finite element;Neural network; Tower crane \\ Correspondence to:Yang Zuo/neilii4886@163.com
}

\begin{abstract}
In order to reduce the probability of crane safety accidents, a method based on radial basis neural network is proposed to quickly obtain the stress spectrum and calculate the remaining life of the crane. Firstly, taking an in-service tower crane as an example, an ANSYS finite element model is established based on actual parameters, and the finite element model is statically analyzed to obtain the location of the dangerous point. Secondly, the typical operating conditions of the crane are simulated. The position of the trolley and the lifting load are used as the input layer while the equivalent stress value at any point is used as the output layer to train the radial basis neural network model. Using the trained radial basis neural network model can obtain time-stress curve at any point quickly. Finally the remaining life is assessed based on the fracture mechanics method. The results show that this method that using the radial basis function neural network model to obtain the time-stress curve at any point can greatly save the cumbersome process and a lot of investment in the field measurement of the crane, and also provides a reliable basis for the long-term safe use and later maintenance of the crane.
\end{abstract}

\section{Introduction}

As a common lifting equipment in daily life, tower cranes are widely used in the field of building construction. It is composed of three parts: metal structure, working mechanism and electrical system. Each working cycle needs to go through two processes of lifting and unloading ${ }^{[1]}$. As the main bearing structure, the metal structure has a service life. If it exceeds its service life, continuing to use it will cause serious production accidents and cause irreparable personnel and property losses ${ }^{[2]} \mathrm{By}$ analyzing the cases of 1,200 tower crane's accidents, the results showed that the accidents caused by the fatigue of the tower crane accounted for $45 \%{ }^{[3]}$. It is extremely necessary to evaluate the fatigue life of the tower crane for reducing the probability of tower crane safety accidents and protecting personnels and equipments. Due to the uncertainty and complexity of the tower crane's working environment, it is difficult to calculate the fatigue life of the tower crane.
The analysis methods of fatigue life can be roughly divided into two categories, respectively data collection through field experiments and simulation calculation through computers. Both methods have their own advantages and disadvantages. The calculation results can be obtained efficiently through simulation method. However, this method is just a theoretical assumption and inference of actual working conditions. Therefore, it has certain errors compared with the actual situation. The results that are obtained by the method of experiments are accurate, but it pays high costs, takes long period, and actual operates difficultly.

$\mathrm{N}$ shamsaei directly conducted tests on specimens with the same or similar structure to obtain the required fatigue life data ${ }^{[4]}$. This method is accurate and feasible. However, if the structure is too large and too complicated, it will take a lot of manpower, economic and time costs. So this method is not realistic. Symons and Davis's impact failure specimens of carbon fiber composite material's were tested for fatigue. The technology of ultrasonic 
scanning was used to scan the specimens. The progress of fatigue damage was judged by monitoring the changes of hysteresis and modulus in specimen. And the 3D map of the damage area was formed by $\mathrm{X}$-ray irradiation. Their test results showed that when the impact energy was increased from 5 joules to 10 joules under a given cyclic stress level, the fatigue life was shortened by about ten years ${ }^{[5]}$ Antonino Risitano evaluated fatigue damage based on the energy loss coefficient. By loading a sufficient number of loads on 304 stainless steel and recording them, comparing the Wöhler curve with the time curve which was obtained based on the energy loss coefficient and the Palmgren-Miner rule, the results showed that the fatigue life can be easily predicted ${ }^{[6]}$.

The data obtained through the experiment can accurately reflect the actual life, but at the same time it will consume a lot of time and experimental cost. So this method has a degree of limitations. In terms of computer simulation, Lu Yaohuil ${ }^{[7]}$ calculated the load spectrum under random conditions through the method of vehicle system dynamics. Based on the standards compiled by the German Mechanical Engineering Committee, the accelerated test load spectrum under different load ratios were compiled, and the acceleration coefficients under the corresponding load ratio conditions were obtained through finite element calculations. The linear cumulative damage theory and the nonlinear cumulative damage theory were used to compare the influence of the loading sequence on the calculation results of the fatigue life. It provides a theoretical basis for the accelerated life test method and the calculation of the fatigue life. Gao Yunkai[ ${ }^{[8]}$ proposed a simple and convenient method for accelerated fatigue test of car body bench, which simplified the load spectrum and verified its effectiveness through simulation experiments. This method establishes a multi-body dynamic model that satisfies certain conditions of accuracy and obtains the position of the human body load randomly distributed by the rain flow counting method and some related statistical theories. This method compiles and simplifies the programmed load spectrum. Through comparative research and analysis, the simulation results of the programmed load spectrum obtained by the modeling are consistent with each other in the distribution of fatigue life and loss, which demonstrates the effectiveness of the method.
In view of the complexity of the excavating manipulator's load, Zhu Jianxin ${ }^{[9]}$ proposes a method for analyzing the remaining fatigue life based on the simulated load spectrum. Henryk Tomaszek $^{[10]}$ converted the variable fatigue cycle actual load spectrum into a uniform load spectrum with weighted cycles, which was used to evaluate the remaining fatigue life of aircraft structures with initial cracks.

Based on the above background, this paper takes the tower crane as the research object, and proposes a method that combines actual measurement and simulation to calculate the fatigue life of the tower crane. This method combines the advantages of field measurement and computer simulation. Through the establishment of ANSYS finite element model, the dangerous points of the tower crane are obtained, the operation data of the tower crane within a period of time is measured and the neural network model is used to quickly obtain the load spectrum of the tower crane for life calculation.

\section{Determination of the dangerous}

\section{point}

The research object of this paper is an in-service tower crane.When being designed, tower cranes will be equipped with some auxiliary components in order to complete some specific functions. The influence of such equipment is usually negligible, when analyzing the structural strength. Therefore, when establishing the finite element model, these components are reasonably simplified in order to increase the calculation speed, reduce the calculation time and unnecessary calculation resources. For some parts that have little effect on the structural strength, They are ignored when modeling. What' $s$ more, the complicated parts of the connection position are treated equivalently. Through this simplification, the effectiveness of the model can be ensured while reducing the workload. After analyzing the actual working conditions of the tower crane and combining with the current crane design specifications, this article simplifies the ANSYS model when building the model. The unit types selected for each component are shown in Table 1.

Table 1. Selection of tower crane finite element .

\begin{tabular}{c|c}
\hline Part & Element type \\
\hline $\begin{array}{c}\text { Tower crane body, balance } \\
\text { arm, lifting arm }\end{array}$ & BEAM188 \\
\hline $\begin{array}{c}\text { Crane cab, hoisting weight, } \\
\text { hoisting hook, counterweight }\end{array}$ & MASS21 \\
\hline Draw bar & LINK180 \\
\hline
\end{tabular}




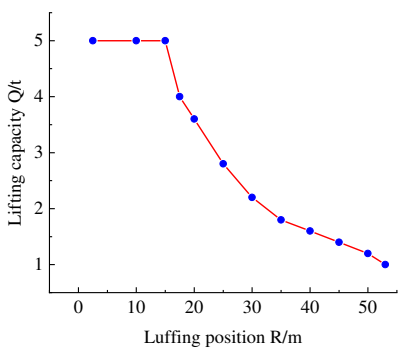

Fig. 1. Hoisting characteristic chart .

The dissertation selected five typical working conditions as shown in Fig. 1 to conduct a static analysis of dangerous working conditions by summarizing the accident cases of tower crane and the lifting characteristics curve of the tower crane as shown in Fig.2, including the luffing trolley located at the minimum luffing position, the inner lifting point, the midpoint of the two lifting points, the outer lifting point and the maximum luffing.

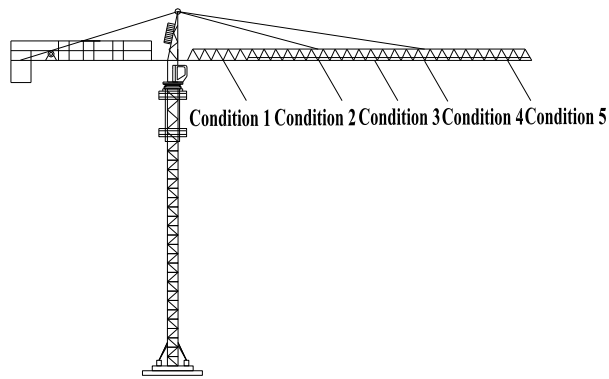

Fig. 2.Schematic diagram of typical working conditions

The static analysis of these five working conditions is carried out, and the results of the static analysis are shown in Fig. 3 and 4. It can be seen from the figure, the trolley is located at the minimum luffing position under No.1 working condition, the lifting weight is $4 \mathrm{t}$, the maximum stress is $118.57 \mathrm{MPa}$ and the maximum deformation is $262.72 \mathrm{~mm}$; the trolley is located at the inner lifting point under No.2 working condition, the lifting weight is $4 \mathrm{t}$, the maximum stress is $116.2 \mathrm{MPa}$ and the maximum deformation is $259.92 \mathrm{~mm}$; the trolley is located at the midpoint of the two lifting points under No.3 working condition, the lifting weight is $2 t$, the maximum stress is $102.81 \mathrm{MPa}$ and the maximum deformation is $255.66 \mathrm{~mm}$; the trolley is located at the outer lifting point under No.4 working condition, the lifting weight is $1.5 \mathrm{t}$, the maximum stress is $77.40 \mathrm{MPa}$ and the maximum deformation is $252.03 \mathrm{~mm}$; the trolley is located at the maximum luffing position under No.5 working condition, the lifting weight is $1 \mathrm{t}$, the maximum stress at this time is $90.35 \mathrm{MPa}$ and the maximum deformation is $259.92 \mathrm{~mm}$. The specific data is shown in Table 3.4 .

The static analysis obtained that the stress value is larger at 1982 points of the connection of the tower and the tower arm, 1876 points of the maximum luffing position, and 1261 points of the minimum luffing position. According to the structural load analysis of the tower crane, these points are subjected to the highest stress and the damage due to alternating load is relatively greater during the operation of the tower crane. Compared with other points, the probability of fatigue failure at these points is also greater and the life consumption is faster. These nodes are selected as dangerous points in the subsequent calculation.

Table 2. Statics operating conditions .

\begin{tabular}{|c|c|c|c|c|}
\hline Conditions & $\begin{array}{c}\text { Trolley } \\
\text { position }\end{array}$ & $\begin{array}{c}\text { Hoisting } \\
\text { weight }\end{array}$ & $\begin{array}{c}\text { Maximum } \\
\text { stress/MPa }\end{array}$ & $\begin{array}{c}\text { Maximum } \\
\text { deformation }\end{array}$ \\
\hline Condition1 & $\begin{array}{l}\text { minimum } \\
\text { luffing } \\
\text { position }\end{array}$ & $4 t$ & 118.57 & 262.71 \\
\hline Condition2 & $\begin{array}{c}\text { inner } \\
\text { lifting point }\end{array}$ & $4 t$ & 116.2 & 259.92 \\
\hline Condition3 & $\begin{array}{c}\text { the } \\
\text { midpoint } \\
\text { of the two } \\
\text { lifting } \\
\text { points }\end{array}$ & $2 t$ & 102.81 & 255.66 \\
\hline Condition4 & $\begin{array}{c}\text { outer } \\
\text { lifting point }\end{array}$ & $1.5 t$ & 77.40 & 252.03 \\
\hline Condition5 & $\begin{array}{l}\text { maximum } \\
\text { luffing } \\
\text { position }\end{array}$ & $1 \mathrm{t}$ & 90.35 & 259.92 \\
\hline
\end{tabular}
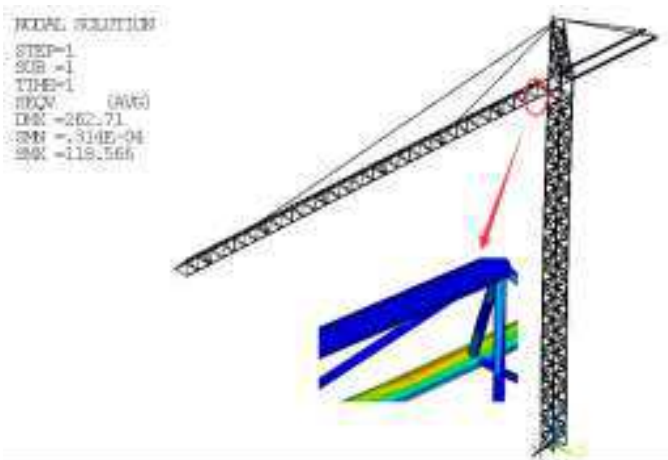

a. The trolley is at the minimum luffing position

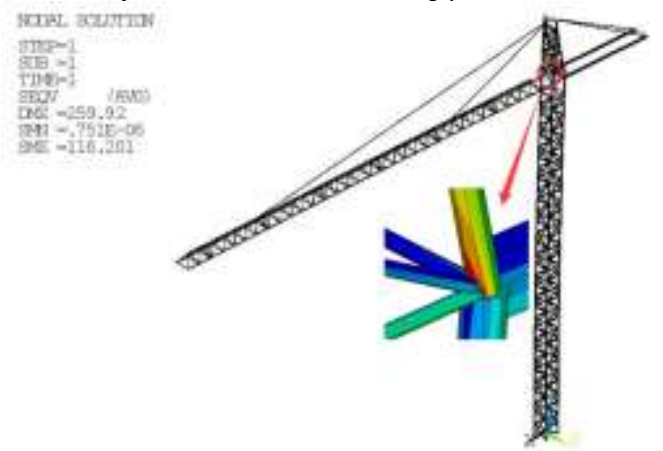

b. The trolley is located at the inner hoisting point 


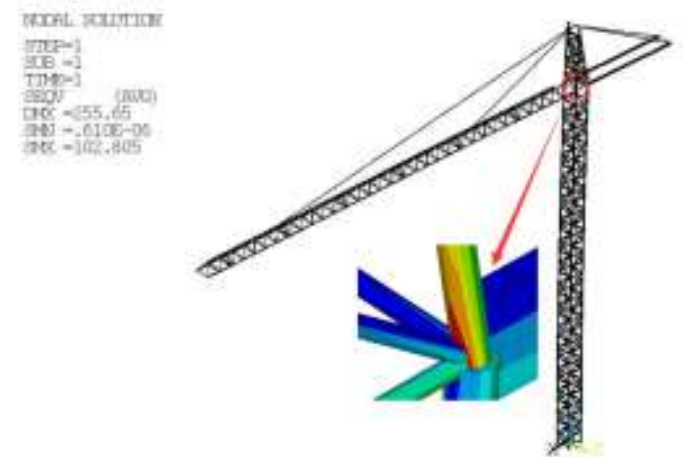

c. The trolley is located at the midpoint of the two lifting points

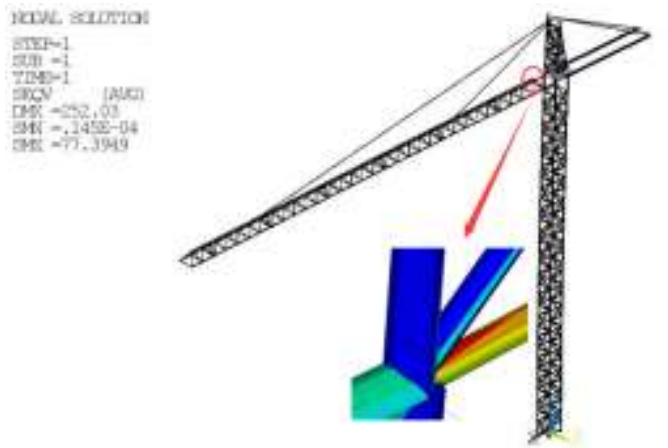

d.The luffing trolley is located at the outer lifting point

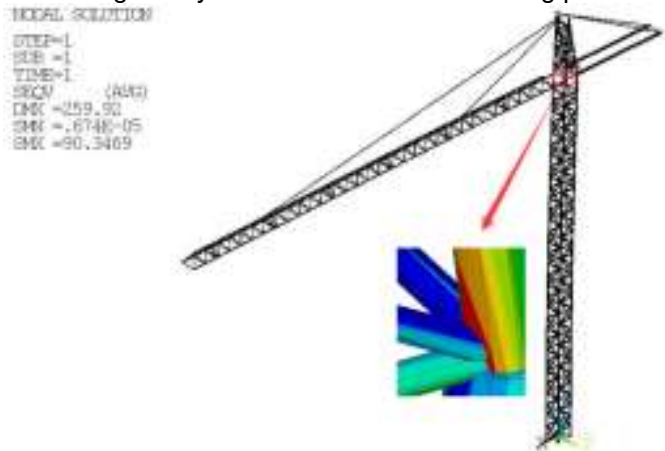

e. The luffing trolley is located at the maximum luffing position

Fig. 3.Static analysis of typical working conditions .

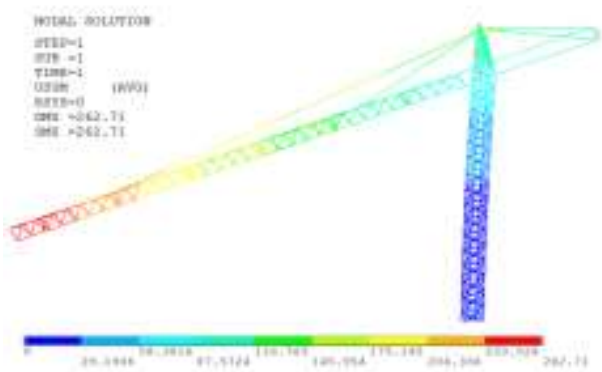

a. The trolley is at the minimum luffing position

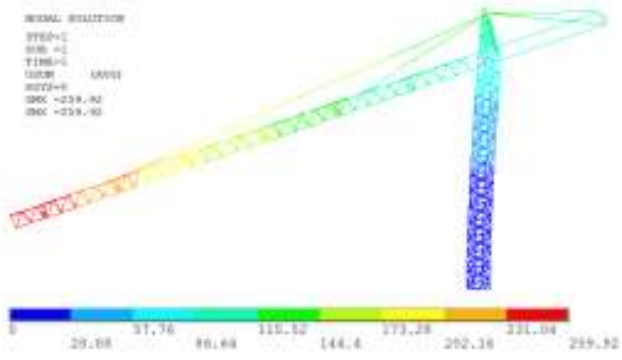

b. The trolley is located at the inner hoisting point

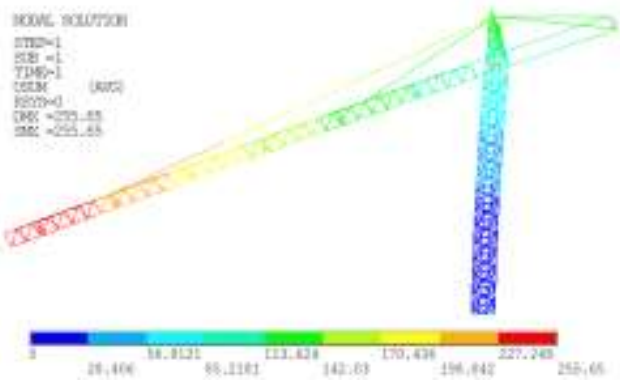

c. The trolley is located at the midpoint of the two lifting points

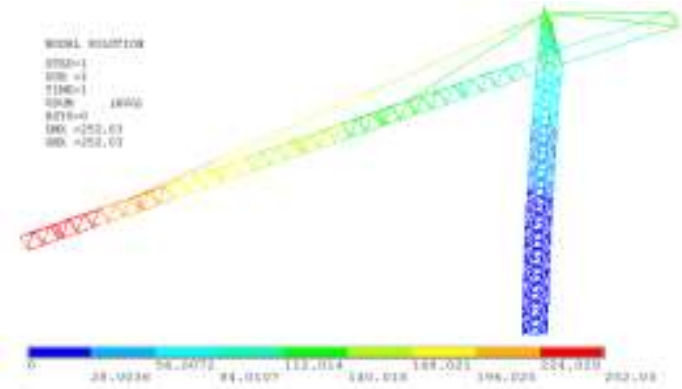

d.The luffing trolley is located at the outer lifting point

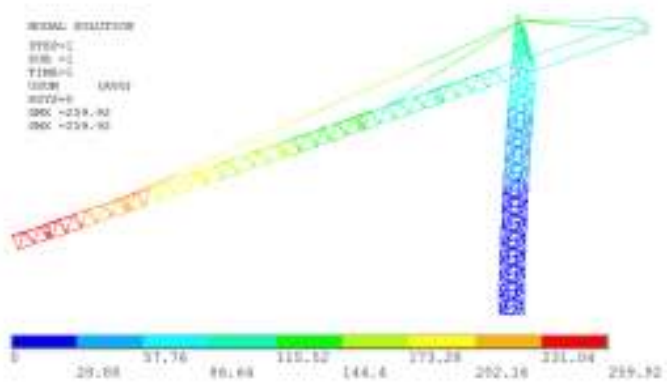

e. The luffing trolley is located at the maximum luffing position

Fig.4 Deformation nephogram of typical working conditions

Since the tower crane is made of metal parts connected by welding, and cracks will inevitably form during the welding process. Therefore, point 1244 at the connection of the outer draw bar and lifting arm and point 1644 at the connection of the inner draw bar and lifting arm are also taken as dangerous points. At the same time, special points of the luffing trolley in operation, point 1333 at the inner hoisting point and point 1510 at the outer hoisting point are also selected as dangerous points for calculation. The final position of the selected dangerous points is shown in Table 3. 
Table 3. Dangerous point position .

\begin{tabular}{c|c}
\hline Dangerous points & Position \\
\hline 1244 & $\begin{array}{c}\text { the connection of the } \\
\text { outer draw bar and lifting } \\
\text { arm }\end{array}$ \\
\hline 1261 & $\begin{array}{c}\text { minimum luffing } \\
\text { position }\end{array}$ \\
\hline 1333 & the inner hoisting point \\
\hline 1510 & the outer hoisting point \\
\hline 1644 & $\begin{array}{c}\text { the connection of the } \\
\text { inner draw bar and lifting } \\
\text { arm }\end{array}$ \\
\hline 1876 & $\begin{array}{c}\text { maximum luffing } \\
\text { position }\end{array}$ \\
\hline 1982 & $\begin{array}{c}\text { the connection of the } \\
\text { tower and the tower arm }\end{array}$ \\
\hline
\end{tabular}

\section{Neural Network Prediction}

Artificial neural networks are a "sub-symbolic" approach to problem-solving. It usually can solve complex nonlinear problems with multiple local extremes based on complex or incomplete data ${ }^{[11-12]}$. Since the parameters that determine the magnitude of the stress values at the dangerous points during the lifting process of the crane are the lifting load and the lifting and unloading position ${ }^{[13]}$. Therefore, the lifting load and trolley position of the crane is used as the input layer of the radial basis neural network, and the output layer is the equivalent stress value at any desired location point, and the model is shown in Fig.5.

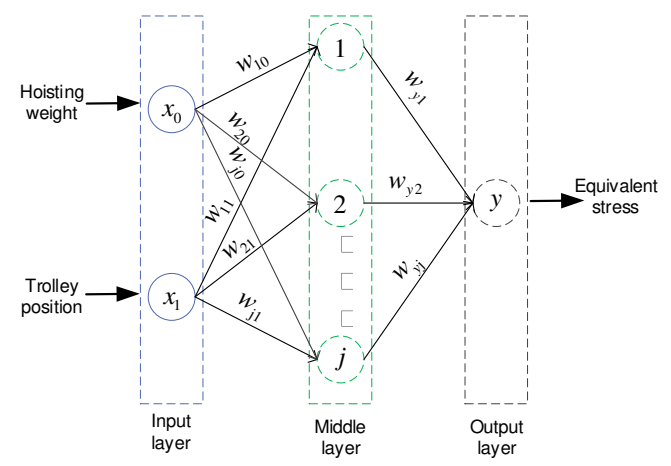

Fig. 5.Neural network model diagram .

The input of the $i_{\text {th }}$ neuron in the middle layer is:

$$
k_{i}^{q}=\sqrt{\sum_{i}\left(\lambda-X_{j}^{q}\right)^{2} \times \zeta}
$$

where $\lambda$ is the weight vector, $X q$ is the $q_{\text {th }}$ input vector, and $\zeta$ is the threshold value.

The output of the $i_{\text {th }}$ neuron in the middle layer is:

$$
\begin{aligned}
r & =\exp \left(-\left(k_{i}^{q}\right)^{2}\right) \\
& =\exp \left(\left(-\left\|w l_{i}-X^{q}\right\| \times \xi_{i}\right)^{2}\right)
\end{aligned}
$$

The threshold $\zeta$ of the radial basis function regulates the sensitivity of the function, but in practice, it is more common to use another expansion constant $C$. In the toolbox of the Matlab neural network, the relationship between $\zeta$ and $C$ is:

$\xi=\frac{0.8326}{C_{i}}$

At this time, the output of the neuron in the middle layer becomes

$$
\begin{aligned}
g_{i}^{q} & =\exp \frac{\sqrt{\sum\left(\lambda_{j}-X_{j}^{q}\right)^{2} \times 0.8326}}{C_{i}} \\
& =\exp \left(-0.8326^{2} \times\left(\frac{\left.\left\|\lambda-X_{q}\right\|\right)^{2}}{C_{i}}\right)\right)
\end{aligned}
$$

The input of the output layer is the weighted sum of the outputs of each intermediate layer neuron:

$$
y^{q}=\sum_{i=1}^{n} r_{i} \times w_{2 i}
$$

To determine each parameter of the neural network, the established finite element model is simulated for typical working conditions. In this paper, five typical working conditions are selected to simulate the operation of the tower crane, as shown in Table 4. The change of load step is $\Delta 0.2 \mathrm{t}$; a load of a tower crane from $0.2 \mathrm{t}$ to $2 \mathrm{t}$; the luffing trolley moves from the lifting position to the unloading position. Then, the finite element stress analysis of simulated tower crane moving load is carried out, which can obtain the equivalent stress value of any point on any section of crane structure with the change of trolley position and lifting load. Taking the equivalent stresses of different nodes as learning samples, the radial basis neural network is trained.The Fig. 6 shows that the stress time history of dangerous points under various working conditions when the lifting weight of the trolley is $0.2 \mathrm{t}$.

Table 4. Dynamic analysis conditions .

\begin{tabular}{c|c|c}
\hline Conditions & lifting position & unloading position \\
\hline Condition1 & $\begin{array}{c}\text { minimum luffing } \\
\text { position }\end{array}$ & $\begin{array}{c}\text { the midpoint of the } \\
\text { two lifting points }\end{array}$ \\
\hline Condition2 & $\begin{array}{c}\text { minimum luffing } \\
\text { position }\end{array}$ & $\begin{array}{c}\text { the inner hoisting } \\
\text { point }\end{array}$ \\
\hline
\end{tabular}




\begin{tabular}{c|c|c}
\hline Condition3 & $\begin{array}{c}\text { the midpoint of the } \\
\text { two lifting points }\end{array}$ & $\begin{array}{c}\text { the outer hoisting } \\
\text { point }\end{array}$ \\
\hline Condition4 & $\begin{array}{c}\text { minimum luffing } \\
\text { position }\end{array}$ & $\begin{array}{c}\text { the outer hoisting } \\
\text { point }\end{array}$ \\
\hline Condition5 & $\begin{array}{c}\text { the inner hoisting } \\
\text { point }\end{array}$ & $\begin{array}{c}\text { maximum luffing } \\
\text { position }\end{array}$ \\
\hline
\end{tabular}

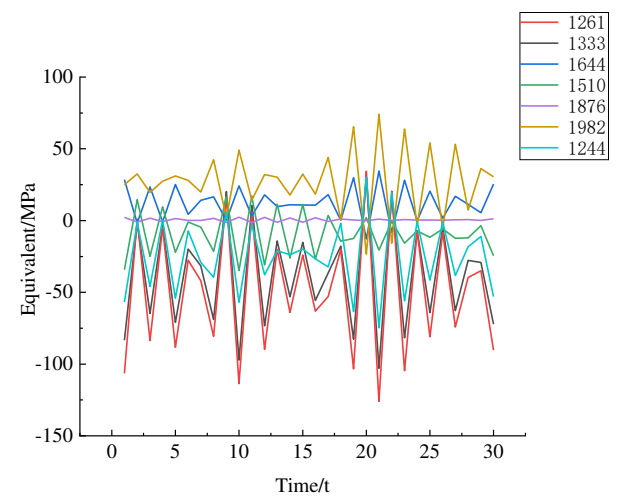

a. Stress time history of $0.2 \mathrm{t}$ in working condition 1

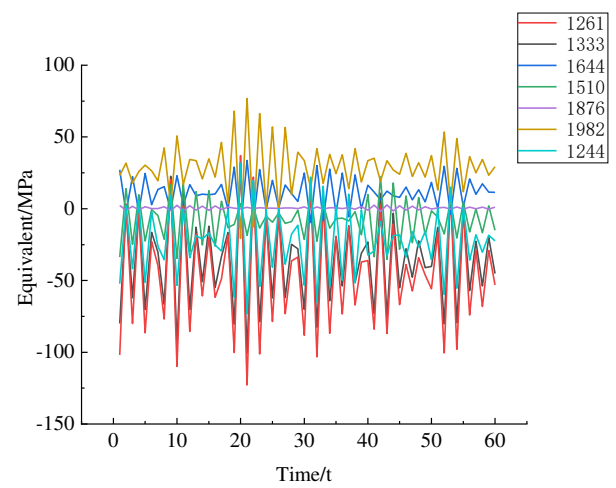

b. Stress time history of $0.2 \mathrm{t}$ in working condition 2

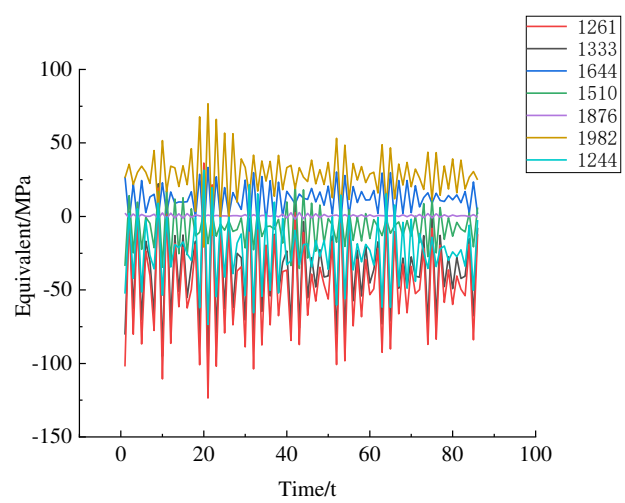

c. Stress time history of $0.2 t$ in working condition 3

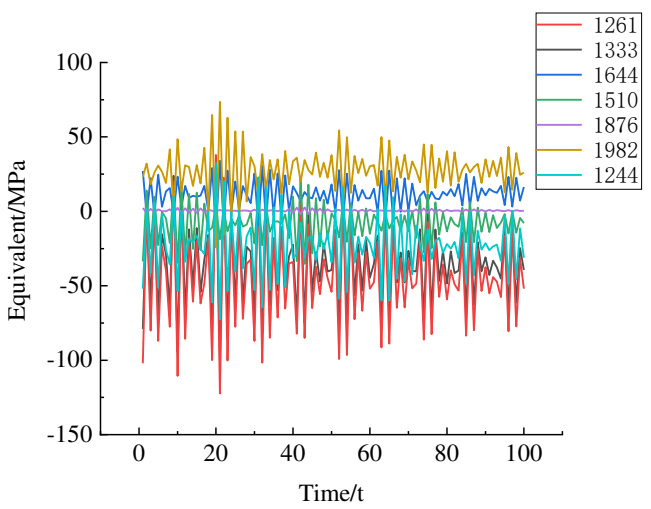

d. Stress time history of 0.2 t in working condition 4

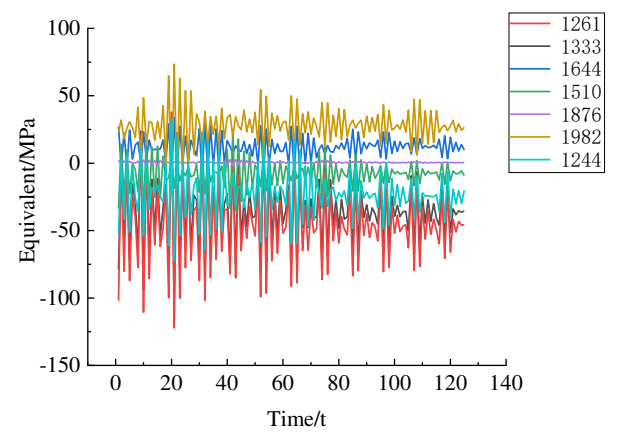

e. Stress time history of $0.2 t$ in working condition 5

Fig. 6.0.2t stress time history of each working condition .

Through the dynamic analysis of the tower structure's hazard points and the comparative analysis of the data, it is found that the dangerous points 1982, 1644, 1333, and 1261 are subjected to a large stress value, and these dangerous points are mostly in the connection of the structure where have welding defects, so it is easy to occur stress concentration resulting in fatigue damage. Therefore, only these four points are selected to calculate the remaining life of fatigue in the subsequent calculation to reduce the calculation cost.

The following is an example of the movement of the luffing trolley from the minimum luffing point to the midpoint of the two lifting points when the lifting weight is $0.2 \mathrm{t}$. The finite element calculation results and the position of the trolley under this working condition are input into the trained radial base neural network as shown in Fig.7.

It can be seen from the data in the figure that the error between the predicted results of the neural network and the results of finite element calculation is small and the accuracy rate is high. To reflect the superiority of using the neural network method to obtain the equivalent stress value quickly, the results of each time 
using the finite element analysis (FEA) and neural network prediction were recorded, and these times were collated and the average value was calculated, which showed in Table 5 . Comparison of the average time required to obtain the results, it can be seen that the radial-based neural network is much faster than the FEA in obtaining the equivalent force values at any point of the crane under the same working conditions.

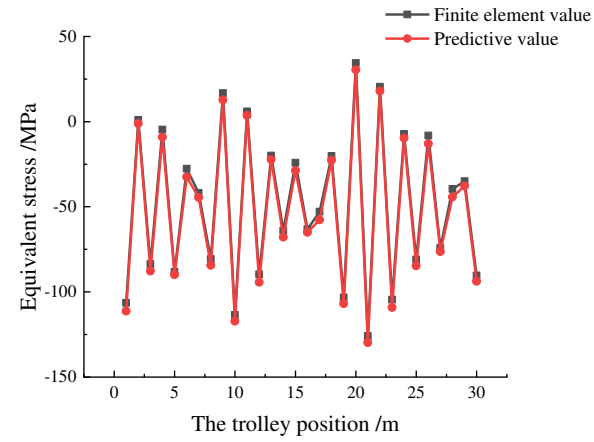

a.1261 point forecast results comparison

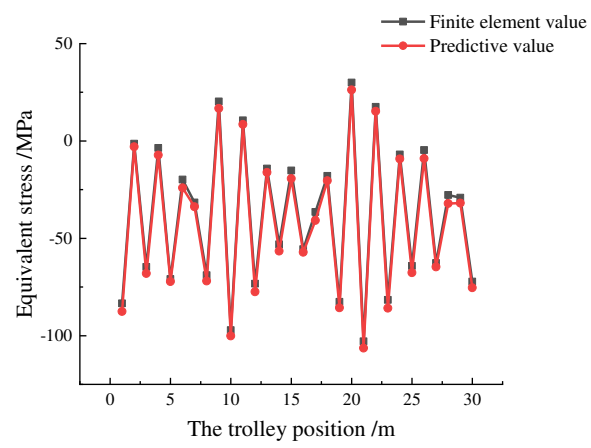

b.1333 point forecast results comparison

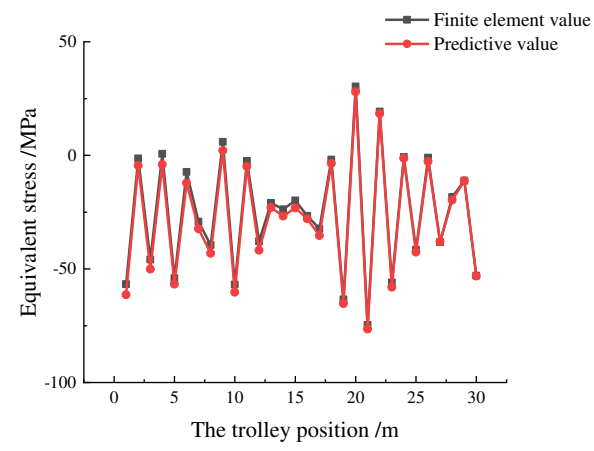

c.1644 point forecast results comparison

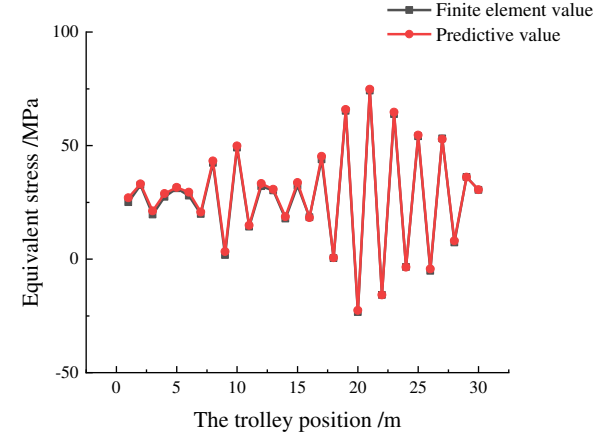

d.1982 point forecast results comparison

Fig.7 Comparison of finite element analysis and neural network prediction results

Table5. Comparison of the time required for the two methods

\begin{tabular}{c|c} 
Method & Time \\
\hline Finite Element Method & $5 \mathrm{~min}$ \\
\hline Neural network prediction & $10 \mathrm{~S}$ \\
\hline
\end{tabular}

\section{Life Calculation}

By monitoring the working cycle of the tower crane in real-time over some time, data is obtained by monitoring the working cycle of the tower crane. The starting point of the luffing trolley operation and the weight of the goods lifted are recorded, which can reflect the actual operation of the tower crane.

The actual data of the tower crane obtained through monitoring is input into the trained neural network model as a prediction sample.The equivalent stress value can be obtained by the neural network model, and the time stress curve is drawn after the rainflow counting process,the results are presented in Fig. 8.

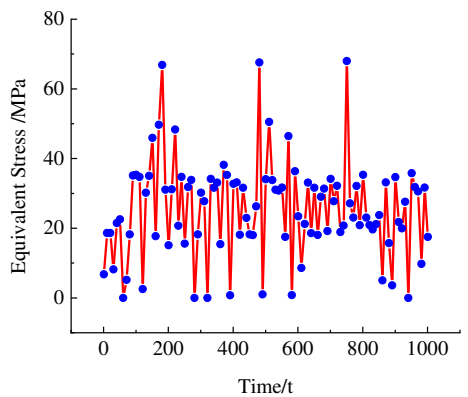

a.Time-stress curves at points 1261 


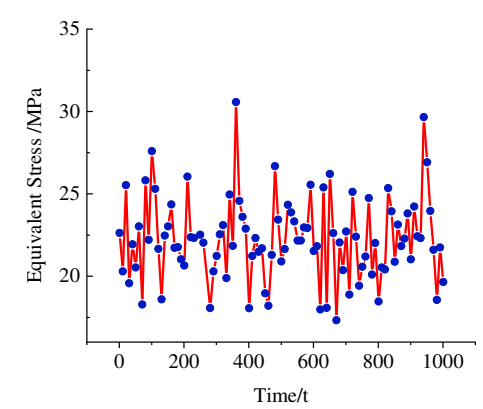

b. Time-stress curves at points 1333

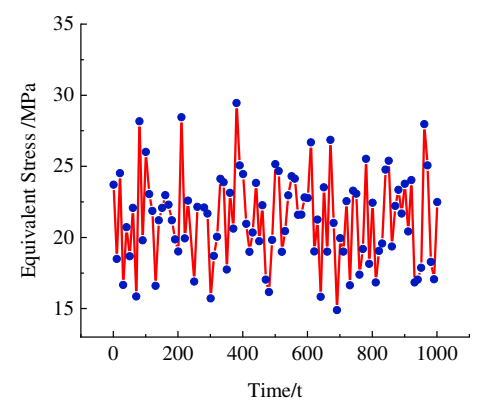

c. Time-stress curves at points 1644

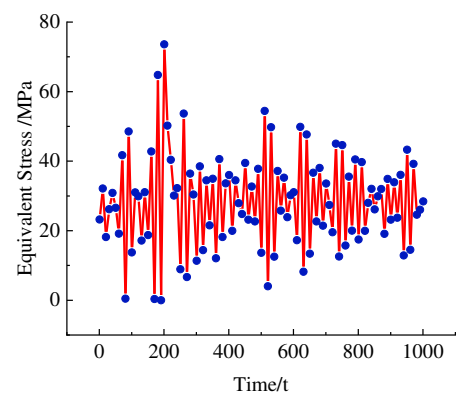

d. Time-stress curves at points 1982

Fig.8 Time-stress curve at dangerous point

The fracture parameters of the Q235 steel is $C=1.83^{*} 10^{-13}, m=2.735829$ through the literature[14], the initial size of cracks in engineering is generally in $0.5-2 \mathrm{~mm}$, this paper takes the $1 \mathrm{~mm}$ as the initial crack size, the number of fatigue cycles of each dangerous point can be calculated through the formula 6 .

$$
\begin{aligned}
N & =\frac{1}{C \times(0.5 m-1) \times(\sqrt{\pi} \times Y \Delta \sigma)^{m}} \\
& \times\left(\frac{1}{a^{0.5 m-1}}-\frac{1}{a_{c}^{0.5 m-1}}\right)
\end{aligned}
$$

where $N$ denotes the life, $Y$ is the correction coefficient of stress-intensity factor, $a$ is the crack length, and $a_{c}$ denotes the critical crack size.

The average lifting time of the tower crane a day is about 35 according to 350 working days of a year for calculation. As a result, the fatigue life of each dangerous point can be calculated, and the specific value is shown in Table 6. As a part of the structure, fatigue damage will lead to fatigue damage of the whole machine, resulting in failure. Therefore, the fatigue life of the point with the least lifetime, 1982, is taken as the life of the whole tower crane, the fatigue remaining life of the tower crane is about 20.28 years.

Table6. Fatigue life of each dangerous point .

\begin{tabular}{c|c|c}
\hline $\begin{array}{c}\text { Dangerous } \\
\text { point }\end{array}$ & Cycles & Life/years \\
\hline 1261 & $2.9097^{\star} 10^{5}$ & 23.75 \\
\hline 1333 & $5.4056^{\star} 10^{5}$ & 44.13 \\
\hline 1644 & $6.5688^{*} 10^{5}$ & 53.62 \\
\hline 1982 & $2.4847^{*} 10^{5}$ & 20.28 \\
\hline
\end{tabular}

\section{Conclusions}

In this paper, the fatigue life of a tower crane in service is estimated by neural network model, and the analysis results provide a reliable basis for the long-term safe use and later maintenance of the crane, the specific conclusions are as follows.

(1) According to the actual geometric parameters, a model of a certain type of tower crane was established through the finite element analysis software ANSYS combined with finite element theory. According to the lifting curve of the tower crane and the analysis of related accidents, this paper selected five typical working conditions of the tower crane for mechanical performance analysis. The stress cloud map of the tower crane under each working condition is obtained through the static analysis, the location of the seven dangerous points are finalized through the results of the static analysis and the characteristics of the tower crane structure.

(2) Applying the radial basis neural network to obtain the time-stress curve is a new method to obtain the time stress curve for the randomness of the working environment of the 
crane use, which is different from the traditional test and simulation.

(3) The application of the trained neural network model achieved the rapid acquisition of the time stress curve for any node, greatly saving the crane field measurement of the tedious process and a large number of inputs. Also, it achieves rapid acquisition of time stress curve to calculate the fatigue remaining life and complete the remaining life estimation of the tower crane fatigue.

\section{References}

[1] Qiang Lv,Identification and Control of Hazard in Water Tower Crane Assembly Process, Anhui Architecture, 2011,18(03):81-82.

[2] National Natural Science Foundation of China, Report on the Development Strategy of Mechanical Engineering(2011-2020),Science Press, Beijing. China, (2010).

[3] Yingli Zhang, Tower crane safety technology,China Petrochemical Press, Beijing, China, (2008).

[4] N Shamsaei, A Fatemi. Deformation and fatigue behaviors of case-hardened steels in torsion: Experiments and predictions. International Journal of Fatigue,2009, (31):1386-1396.

[5] Digby D. Symons.Fatigue testing of impact-damaged T300/914 carbon-fibre-reinforced plastic, Composites Science and Technology, 60 (2000) 379-389.

[6] Antonino Risitano.Cumulative damage evaluation in multiple cycle fatigue tests taking into account energy parameters, International Journal of Fatigue,48 (2013) 214-222.

[7] LU Yaohui,ZHANG Xing and ZHANG Shuxiang, Load Spectrum Compilation and Analysis of Acceleration Life Test for High Speed Train Carbody, Journal of Mechanical Engineering, 2017,53(24):151-160.

[8] Yunkai Gao, Jingpeng Han and Jianguang Fang. Programmed Load Spectrum for Fatigue Bench Test of a Vehicle Body,SAE International Journal of Materials and Manufacturing, 2016,3(9):605-613.

[9] ZHU JIanXin,LUO BoYi and SONG YaGong, Research of fatigue life simulation based on ANSYS for excavator boom, Computer Applications and Software,2017,34(2):112-117.

[10] Henryk Tomaszek,Michal Jasztal and Mariusz Zieja. Application of the paris formula with $\mathrm{m}=2$ and the variable load spectrum to a simplified method for evaluation of reliability and fatigue life demonstrated by aircraft components, Eksploatacja i Niezawodnosc-Maintenance and
Reliability, 2013, 15 (4): 297-304.

[11] HaikunWei and Shun-ichiAmari. Dynamics of learning near singularities in radial basis function networks,. Neural Networks, 2008, 7(21):989-1005.

[12] Roger Parloff,Nan WANG and Xiangjie Hu, Taking stock of the deep learning revolution, Science \& Modernization, 2017(10).

[13] WANG AiHong,XU GenNing and GAO YouShan.Random stress spectrum acquisition and fatigue residual life estimate for overhead travelling crane, Journal of Mechanical Engineering,2012, 48(18):192-198.

[14] Zhao Zhangyan,Lei Xinhua and Sun Guozheng Zhao ZhangyanMeasuring Crack Propagation Parameters of Q235 Steel with Experiment,Journal of Wuhan University of Technology ,2003,25 (1):49-51.

\section{Author information}

Yang Zuo, received the Master's degree from Taiyuan University of Science and Technology, Taiyuan, China,in 2021. He is now working in China Railway Sixth Group CO.,LTD.His current research interests cover fatigue life and reliability of mechanical structure. 